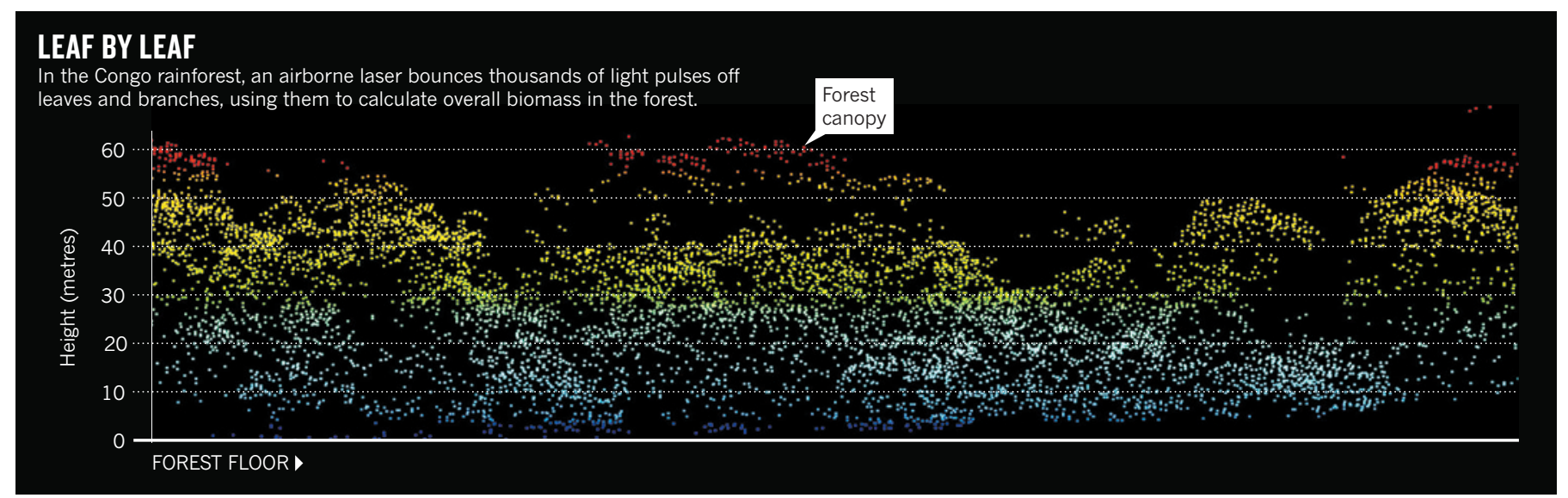

\title{
Congo carbon plan kicks off
}

\section{Democratic Republic of the Congo maps forest biomass to attract carbon credits.}

\section{BY JEFF TOLLEFSON}

$\mathrm{A}$ fter lifting off this week from the chaotic urban jungle of Kinshasa, scientists guided a twin-engine aircraft over the real jungle. With a small onboard laser, they began sweeping the vast rainforest of the Democratic Republic of the Congo (DRC), bouncing photons off leaves and branches. The aim is to measure - and perhaps to preserve the carbon locked up in the tropical forests that cover two-thirds of the country.

The data will also enhance scientists' understanding of tropical forests' role in global climate regulation. "We know very little about the tropics," says Sassan Saatchi, a remotesensing scientist at NASA's Jet Propulsion Laboratory in Pasadena, California, who is leading the data analysis for the project. "If these countries know how to monitor their forests quantitatively, it will help us solve the problem."

The flights are part of a two-year, €6-million (US\$8-million) project, funded by Germany, to combat the kind of tropical deforestation that today accounts for up to $15 \%$ of the world's carbon dioxide emissions. For years, governments have debated a treaty that would allow developed countries to offset their own greenhouse-gas emissions by helping tropical countries to conserve their forests. Negotiations have stalled, but wealthy nations have already pledged several billion dollars to get the scheme started.

The DRC is one of several tropical countries hoping to attract some of that money. But first, it must map biomass across a staggering 155 million hectares - the largest tropical forest in a single country outside Brazil — and then establish a system to monitor deforestation from space. "The country is so huge, it has so much forest, and it's so poor," says Aurélie Shapiro, the project's technical lead with WWF Germany, an environmental group that is managing the project with the DRC. "If the Democratic Republic of the Congo can do it, anybody can."

To help, WWF Germany turned to Saatchi, who has already mapped out carbon across the world's tropics, but at relatively low resolution of 1 kilometre. His calculations suggest that the DRC's forests contain 22 billion to 24 billion tonnes of carbon, equivalent to more than double the greenhouse gases emitted last year. But the measurements need to be more precise, he says, because biomass can vary by up to $50 \%$ between patches of forest. With a map at 100metre resolution, the DRC will be better able to calculate the emissions that would result from clearing a block of forest. That, in turn, would be key information for companies or governments seeking to offset their emissions by protecting DRC land.

The project will start with the laser data collected by planes flying out of Kinshasa (see 'Leaf by leaf'). The team will then begin operating out of more remote airports, many little more than dirt runways in the jungle. The plan is to sample at more than 200 locations, selected to capture different types of forest and to avoid conflict zones in the war-torn country. It is a daunting task that has required more than two years of planning. "We have to carry our fuel with us," says Saatchi. "And we have only limited areas where it's safe to land."

The aerial measurements will cover just half a million hectares, but can be extrapolated to the entire forest through calibration with ground data and satellite imagery. The data are first cross-checked with measurements of tree girth and height at several hundred ground plots - the classic way to calculate forest biomass. The biomass estimates are then used to calibrate imagery from NASA's Landsat spacecraft and radar data from Japan's Advanced Land Observing Satellite, to produce a measure of carbon for all 155 million hectares of jungle.

The DRC is not the only country embarking on large-scale forest measurements. Gabon, in the western Congo Basin, is planning to map its forests using the same technique, and in the past few years Peru has mapped the carbon in its part of the Amazon (see Nature 461, 1048-1052; 2009). Brazil has made less-detailed assessments of forest carbon, but its system for monitoring deforestation is the world's most advanced. Scientists with the country's National Institute for Space Research in São José dos Campos are now helping the DRC to set up a similar system, based on freely available Landsat data, to track deforestation - and ultimately to verify reductions in such losses and sell carbon offsets.

Matthew Hansen, a remote-sensing scientist at the University of Maryland in College Park who works with forest mappers in Kinshasa, says that the DRC project faces hurdles. Much of the deforestation - by urban dwellers seeking wood and charcoal, and by farmers clearing small plots of land - is small-scale and difficult to see by satellite. Constant clouds also complicate the kind of monitoring that Brazil has pioneered.

Large-scale deforestation, which would be easier to monitor, has yet to take off in the Congo Basin, owing in part to political instability. But Hansen fears that could change if investments increase in agriculture projects such as oil-palm plantations. "If that ever happens, you could see some dramatic changes," he says. 